\title{
Microstructure Simulation for Solidification of Magnesium-Zinc-Yttrium Alloy by Multi-phase-field Method Coupled with CALPHAD Database
}

\author{
Satoshi MINAMOTO, ${ }^{1)}$ Sukeharu NOMOTO, ${ }^{1)}$ Atsushi HAMAYA, ${ }^{2)}$ Toshiaki HORIUCHI ${ }^{2)}$ and Seiji MIURA ${ }^{3)}$ \\ 1) Science \& Engineering Systems Division, ITOCHU Techno-Solutions Corporation, Kasumigaseki, Chiyoda-ku, Tokyo 100- \\ 6080 Japan. E-mail: satoshi.minamoto@ctc-g.co.jp $\quad$ 2) Department of Mechanical Systems Engineering, Hokkaido \\ Institute of Technology, Sapporo, Hokkaido 006-8585 Japan. \\ 3) Material Science and Engineering, Hokkaido University,
} Sapporo, Hokkaido 060-8628 Japan.

(Received on May 31, 2010; accepted on July 29, 2010)

\begin{abstract}
The Mg-Zn-Y alloys show a good mechanical strength which can be achieved with the precipitation hardening by intermediate phases ( $X, W$ and / phase) in Mg solid solution ( $\alpha$ phase). However, an accurate control of the microstructure formation is required in order to obtain good mechanical properties. In this study, experimental observations of microstructures of the Mg-Zn-Y system have been performed. Then we have focused on developing CALPHAD (CALculation of PHAse Diagrams) thermodynamic database to obtain the Gibbs free energy to draw phase diagram of the system and to understand the precipitation behavior of the intermediate phases. In order to understand the formation of microstructures, we have performed simulations of solidification of the alloy with use of multi-phase-field method. At the beginning the solidification process has been calculated for a large area, then the zoomed in region of the lamellar structures of the $\alpha$ phase and the $W$ phase have been analyzed. Resulting optimum lamellar spacing reproduce experimental one well.
\end{abstract}

KEY WORDS: magnesium alloy; CALPHAD; solidification; phase field method.

\section{Introduction}

In order to realize high strength of the $\mathrm{Mg}-\mathrm{Zn}-\mathrm{Y}$ alloy using the precipitation hardening by introducing intermediate phases (the $X\left(\mathrm{Mg}_{12} \mathrm{Zn}_{1} \mathrm{Y}_{1}\right)$ phase and $W\left(\mathrm{Mg}_{3} \mathrm{Zn}_{3} \mathrm{Y}_{2}\right)$ phase) in $\mathrm{Mg}$ solid solution (the $\alpha$ phase), ${ }^{1-4)}$ a control of the precipitation behavior is very important. The thermodynamic models of the $\mathrm{Y}-\mathrm{Zn}$ and $\mathrm{Mg}-\mathrm{Zn}-\mathrm{Y}$ system have been evaluated with use of the CALPHAD method ${ }^{5)}$ based on the COST thermodynamic database. ${ }^{6)}$ Another thermodynamic assessment has been carried out based on a firstprinciples method $^{7)}$ except for the ternary intermetallic compounds denoted as $X, W$ and $I$.

Experimentally observations of the ternary intermetallic compounds have been performed in the $\mathrm{Mg}-\mathrm{Zn}-\mathrm{Y}$ system. ${ }^{1-4)}$ Recently, one of our authors has investigated the solubility limit for the $\alpha$ phase and the chemical composition of the $X$ phase in the $\alpha$ phase. ${ }^{8)}$

In the study we revealed that the $W$ phase has non-stoichiometry for the $\mathrm{Mg}$ and $\mathrm{Zn}$ at $25 \mathrm{at} \% \mathrm{Y}$ composition with L2 1 crystal structure, which has different thermodynamic model proposed by previous literature. ${ }^{8)}$ Thus it is necessary to re-build a thermodynamic database to simulate the system by means of CALPHAD technique. The solid solubility range in the $W$ phase and melting point of the $X$ phase and the $I$ phase were evaluated based on our experimental results. Then we performed multi-phase-field simulations coupled with the thermodynamic data to elucidate microstructure evolution. At the beginning we analyzed the region of $80 \mu \mathrm{m} \times 60 \mu \mathrm{m}$ to study the precipitation of the intermetallic phases, then we made another calculations to elucidate the mechanism of the lamellar structure formation of the $\alpha$ phase and the $W$ phase.

\section{Experimental Procedure}

\subsection{Sample Preparations and Observations}

A master ingot of the $97.0 \mathrm{Mg}-1.3 \mathrm{Zn}-1.6 \mathrm{Y}$ (at\%) alloy was prepared from high-purity raw materials; $99.95 \% \mathrm{Mg}$ bar, $99.5 \% \mathrm{Zn}$ sheet and small pieces of $99.99 \% \mathrm{Y}$. These metals were melted in a $31 \mathrm{~mm}$ diameter graphite crucible using a high-frequency induction furnace under high-purity argon atmosphere, and the as-cast ingot size was 20 thick $\times 50$ wide $\times 52$ high $(\mathrm{mm})$. The sample for examination of the liquid-solid coexistence region was cut into 20 thick $\times 4$ square $(\mathrm{mm})$ piece and was encapsulated in lidded $6 \mathrm{~mm}$ diameter graphite crucible, in consideration of the dangers of molten $\mathrm{Mg}$ alloy during water-quenching. And again, a sample for the examination of the liquid-solid coexistence region was encapsulated in quartz tube with highpurity argon gas for an isothermal heat treatment. The isothermal heat treatment was carried out using a vertical 
electrical furnace. The sample for the liquid-solid coexistence region was heated up to approximately $973 \mathrm{~K}$ and held for $30 \mathrm{~min}$ to obtain completely molten state, and was cooled down to the prescribed temperature $(833 \mathrm{~K})$ with a cooling rate of $1 \mathrm{~K} / \mathrm{min}$, and held for $2 \mathrm{~h}$. After the isothermal heat treatment $(833 \mathrm{~K})$, the sample encapsulated in quartz tube was dropped into water, and the quartz tube was immediately broken by quenching.

The microstructure of sample was observed using an electron probe microanalyzer (EPMA; JEOL JXA-8200), and the chemical compositions for phases of the sample were analyzed using wave length dispersive X-ray spectroscopy (WDS). Moreover, the thin film sample was made by using focused ion beam system (FIB; JEOL JEM9320FIB). The microstructure of thin film sample was observed using transmission electron microscope (TEM; JEOL JEM-2000FX), and the chemical compositions for phases of the thin film sample were analyzed using energy dispersive X-ray spectroscopy (EDS).

\section{Calculation Methods}

The assessment of CALPHAD thermodynamic database based on experimental data was performed with ThermoCalc software package. ${ }^{9)}$ Then the multi-phase-field simulations coupled with the revised CALPHAD thermodynamic database were carried out with MICRESS software package. $^{10)}$

\subsection{CALPHAD Technique}

Phase equilibrium is able to be calculated by means of CALPHAD approach by calculating minimization of the Gibbs free energy for many phases. The total Gibbs free energy of structure $\phi$ can be described as,

$$
G_{m}^{\phi}=\sum_{i} x_{i}^{0} G_{i}^{\phi}+R T \sum_{i} x_{i} \ln x_{i}+{ }^{e x} G_{m}^{\phi}
$$

where $x_{i},{ }^{0} G_{i}{ }^{\phi}, R$ and $T$ are the mole fraction of element $i$, the Gibbs free energy of $i$ with structure $\phi$, the gas constant, and the temperature in Kelvin, respectively. The first term on the right hand side is a linear combination of the pure Gibbs free energy. The second term is the ideal entropy of mixing. The third term is the excess Gibbs energy which is given by the following equation in an $A-B$ system,

$$
{ }^{e x} G_{m}^{\phi}=x_{A} x_{B} L_{A, B}^{\phi}
$$

where $L_{A, B}^{\phi}$ is the interaction parameter between the elements $A-B$ in $\phi$ phase. It is written in the form of Redlich-Kister polynomials, ${ }^{11)}$

$$
L_{A, B}^{\phi}=\sum_{v=0}^{n}{ }^{v} L_{A, B}^{\phi}\left(x_{A}-x_{B}\right)^{v}
$$

where $n$ is taken as an arbitrary degree, ${ }^{v} L_{A, B}^{\phi}$ depending on temperature, which is described as follows,

$$
{ }^{v} L_{A, B}^{\phi}={ }^{v} a+{ }^{v} b \times T+\cdots
$$

where ${ }^{v} a,{ }^{v} b$ are constants at the degree is $v$, which should be determined to yield experimental results.

\subsection{Multi-phase-field Approach}

The phase field modeling is well described in Ref. 10). The pair-wise interaction of phase $i$ with all other phases $j$ in case of a double obstacle potential are considered. The numerical methods of multi-phase-field approach coupled with CALPHAD thermodynamic database are summarized. ${ }^{12)}$ The microstructure evolves according to a decrease of total free energy. A set of multi-phase field equations could be derived based on thermodynamic principles,

$$
\begin{aligned}
& \frac{d \phi_{i}}{d t}=\sum_{j} \mu_{i j}\left[\sigma_{i j}\left(\phi_{i} \nabla^{2} \phi_{j}-\phi_{j} \nabla^{2} \phi_{i}+\frac{\pi^{2}}{2 \eta_{i j}^{2}}\left(\phi_{i}-\phi_{j}\right)\right)\right. \\
& \left.+\frac{\pi}{\eta_{i j}} \sqrt{\phi_{i} \phi_{j}} \Delta G_{i j}\right]
\end{aligned}
$$

where $\phi$ denotes phase field parameter, $\eta$ is interface thickness, $\Delta G$ is the driving force, $\sigma$ is interface energy and $\mu$ is interface mobility.

The expression of the time evolution of concentration field is described by diffusion equation,

$$
\dot{\vec{c}}=\nabla\left[\sum_{i} \phi_{i} \dot{\vec{D}}_{i} \nabla \dot{\vec{c}}_{i}\right]
$$

where $D_{i}$ is interdiffusion matrix.

\section{Results and Discussion}

\subsection{Experimental Results}

The backscattered electron image (BEI) of the casted $\mathrm{Mg}$ alloy is shown in Fig. 1. Dark region is the $\alpha$ phase, bright area is a region of coexistence of the $X$ phase and lamellar (the $\alpha$ phase and the $W$ phase) structure.

A magnified image of Fig. 1 is shown in Fig. 2. The coexistence of the $\alpha$ phase and the plate-like $X$ phase is clearly observed.

\subsection{CALPHAD Thermodynamic Parameters}

In the calculations we used previous reported thermodynamic parameters based on first-principles calculations ${ }^{7)}$ and the thermodynamic data for the intermetallic com-

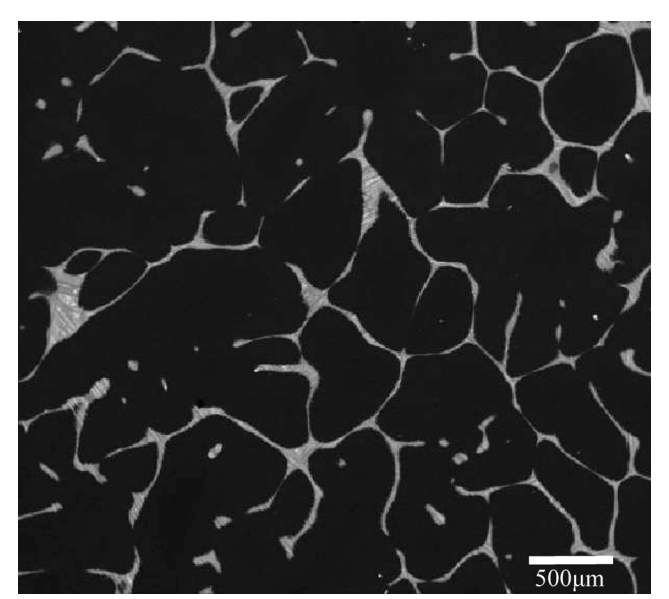

Fig. 1. The backscattered electron image observed by EPMA for the $\mathrm{Mg}-\mathrm{Zn}-\mathrm{Y}$ alloy. 
pounds of the $X, W$ and $I$ phases are based on the another literature data. ${ }^{5)}$ However the sublattice model for the $W$ phase was rebuild based on the experimental results. The $W$ phase normally denotes the $\mathrm{Mg}_{3} \mathrm{Zn}_{2} \mathrm{Y}_{3}$ with $\mathrm{L} 2_{1}$ crystal structure. Though the previous CALPHAD thermodynamic parameter has a 20 at $\%$ Y constant line, ${ }^{5)}$ one of authors have revealed that the crystal structure of the $W$ phase is basically $\mathrm{L} 2{ }_{1}{ }^{8)}$ which has a 25 at $\%$ Y constant line and in this study sublattice model of the phase are modeled based on L2 ${ }_{1}$ crystal structure and this phase is treated as a non-stoichiometric compound. Therefore we revised a model that 25 at $\% \mathrm{Y}$ constant line and $\mathrm{Mg}$ and $\mathrm{Zn}$ solubility are taken into account.

The $\mathrm{Mg}_{12} \mathrm{Zn}_{1} \mathrm{Y}_{1}$ is denoted by the $X$ phase with a long periodic stacking ordered structure (LPSO), which contributes to the high mechanical strength. The thermodynamic model of the $X$ phase is build as a stoichiometric compound.

The $I$ phase is considered to be a quasi-crystal structure based on the diffraction analysis. ${ }^{13-15)}$ In this study the thermodynamic parameters for the $I$ phase were taken from Ref. 5) as a stoichiometric compound, however no consideration for the crystal structure.

The calculated ternary phase diagram appears in Fig 3. Overall thermodynamic parameters for the ternary intermetallic compounds are listed in Table $\mathbf{1 .}$

Calculated liquidus surface projection is shown in Fig. 4.

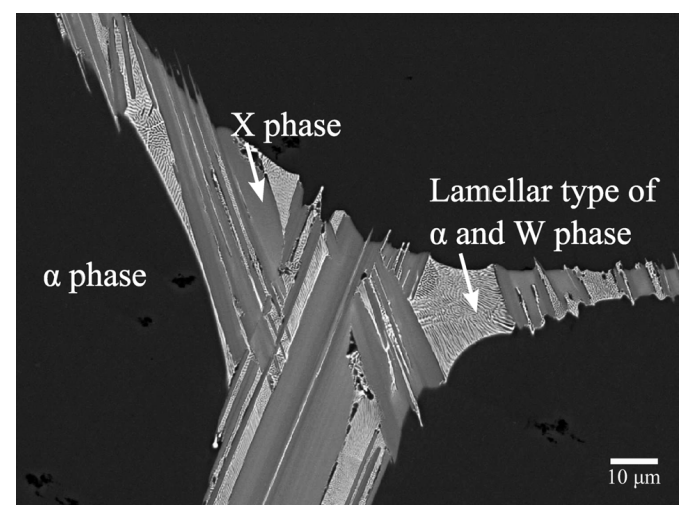

Fig. 2. The backscattered electron images observed by EPMA for $\mathrm{Mg}-1.3 \mathrm{at} \%-1.6 \mathrm{at} \% \mathrm{Y}$ after isothermal heat treatment for $2 \mathrm{~h}$ at $833 \mathrm{~K}$.

\subsection{The Phase Field Modeling}

We performed two types of phase field simulations, one is macro area analysis to understand overall picture of the microstructures, and another is micro scale area analysis in order to understand the growth of the lamellar structures.

\subsubsection{Diffusivities and Interface Energies}

Diffusivity data of the elements in the $\alpha$ phase were taken from MOB2 kinetic database. ${ }^{16)}$ Because the diffusivity data of the $Y$ in the $\alpha$ phase were not available in the literature, the diffusivity of the La in the $\alpha$ phase $^{17)}$ was applied as substitutes.

The interface energies were obtained by empirical calculations or experimental results. An interface energy $\sigma$ between $\alpha$ phases was obtained by following equation. ${ }^{18)}$

$$
\sigma_{\alpha-\alpha}=\frac{3}{2}\left(\frac{N_{A}}{V_{m}}\right)^{2 / 3}\left(\frac{\Delta H_{m}}{N_{A}}\right)
$$

where $N_{A}$ is the Avogadro number, $V_{m}$ molar volume, $H_{m}$ latent heat of melting.

An interface energy between the $\alpha$ phase and the $X$ phase was obtained from a dihedral angle between the $\alpha$ phase and the $X$ phase at the triple point at $723 \mathrm{~K}$ shown as following expression, ${ }^{19)}$

$$
\sigma_{\alpha-X}=\sigma_{\alpha-\alpha} \frac{1}{2 \cos (\theta / 2)}
$$

where $\theta$ is a dihedral angle of $85^{\circ}$ between the $\alpha$ and the $X$ at the triple point of $\alpha-\alpha-X$ at $723 \mathrm{~K}$ based on our experiments.

Table 2. The interface energy $\sigma_{i-j}\left[\mathrm{~J} / \mathrm{m}^{2}\right]$ between $i$ and $j$ phase applied in the simulations. The $\varepsilon$ and $k$ are anisotropy parameters in interface energy and mobility, respectively. An anisotropy is expressed as $\sigma(\theta)=\left(\cos ^{2} \theta+\right.$ $\left.0.1 \sin ^{2} \theta\right) \sigma_{i-j}(1+\varepsilon \cos (k \theta))$.

\begin{tabular}{llll}
\hline \hline Interface & Energy $\left[\mathrm{J} / \mathrm{m}^{2}\right]$ & $\epsilon$ & $k$ \\
\hline$\sigma_{\text {liquid- } \alpha}$ & $1.0 \times 10^{-1}$ & 0.0057 & $6^{20)}$ \\
$\sigma_{\text {liquid-X }}$ & $1.2 \times 10^{-1}$ & 0.0667 & 2 \\
$\sigma_{\text {liquid-W }}$ & $1.2 \times 10^{-1}$ & 0.0133 & 4 \\
$\sigma_{\alpha-\alpha}$ & $2.2 \times 10^{-1}$ & & \\
$\sigma_{\alpha-X}$ & $1.5 \times 10^{-1}$ & & \\
$\sigma_{\alpha-W}$ & $1.5 \times 10^{-1}$ & & \\
\hline
\end{tabular}

Table 1. The re-evaluated thermodynamic parameters for the intermetallic compounds. The thermodynamics parameters for other phases were applied with another Ref. 7). The same sublattice models in Ref. 5) were used except for the sublattice for the $W$ phase, $(\mathrm{Mg})_{0.25}(\mathrm{Y})_{0.25}(\mathrm{Mg}, \mathrm{Zn})_{0.5}$.

\begin{tabular}{llll}
\hline \hline Phase & \multicolumn{1}{c}{ Thermodynamic parameters } & Ref. \\
\hline$H$ & ${ }^{0} \mathrm{G}_{\mathrm{Mg}: \mathrm{Y}: \mathrm{Zn}}^{H}-15{ }^{0} \mathrm{G}_{\mathrm{Mg}}^{h c p} \mathrm{Mg}-15{ }^{0} \mathrm{G}_{\mathrm{Y}}^{h c p}-70{ }^{0} \mathrm{G}_{\mathrm{Zn}}^{h c p}$ & $=-3800000+980 T$ & This work \\
$I$ & ${ }^{0} \mathrm{G}_{\mathrm{Mg}: \mathrm{Y}: \mathrm{Zn}}^{I}-2.7{ }^{0} \mathrm{G}_{\mathrm{Mg}}^{h c p} \mathrm{Mg}-1.6{ }^{0} \mathrm{G}_{\mathrm{Y}}^{h c p}-5.7{ }^{0} \mathrm{G}_{\mathrm{Zn}}^{h c p}$ & $=-387500+115 T$ & This work \\
& ${ }^{0} \mathrm{G}_{\mathrm{Mg}: \mathrm{Y}: \mathrm{Mg}}^{I}-8.4{ }^{0} \mathrm{G}_{\mathrm{Mg}}^{h c p} \mathrm{Mg}-1.6{ }^{0} \mathrm{G}_{\mathrm{Y}}^{h c p}$ & $=-4700.0+50.5 T$ & This work \\
$W \quad$ & ${ }^{0} \mathrm{G}_{\mathrm{Mg}: \mathrm{Y}: \mathrm{Zn}}^{W}-0.25^{0} \mathrm{G}_{\mathrm{Mg}}^{h c p} \mathrm{Mg}-0.25{ }^{0} \mathrm{G}_{\mathrm{Y}}^{h c p}-0.5{ }^{0} \mathrm{G}_{\mathrm{Zn}}^{h c p}$ & $=-40400+7.9 T$ & This work \\
& ${ }^{0} \mathrm{G}_{\mathrm{Mg}: \mathrm{Y}: \mathrm{Mg}}^{W}-0.75{ }^{0} \mathrm{G}_{\mathrm{Mg}}^{h c p} \mathrm{Mg}-0.25^{0} \mathrm{G}_{\mathrm{Y}}^{h c p}$ & $=-4680+2.8 T$ & This work \\
& ${ }^{0} \mathrm{~L}_{\mathrm{Mg}: \mathrm{Y}: \mathrm{Mg}, \mathrm{Zn}}$ & $=-5290$ & This work \\
& ${ }^{1} \mathrm{~L}_{\mathrm{Mg}: \mathrm{Y}: \mathrm{Mg}, \mathrm{Zn}}$ & This work \\
$X$ & ${ }^{0} \mathrm{G}_{\mathrm{Mg}: \mathrm{Y}: \mathrm{Zn}}^{X}-0.86{ }^{0} \mathrm{G}_{\mathrm{Mg}}^{h c p} \mathrm{Mg}-0.08{ }^{0} \mathrm{G}_{\mathrm{Y}}^{h c p}-0.06{ }^{0} \mathrm{G}_{\mathrm{Zn}}^{h c p}$ & $=-8660+2.91 T$ & This work \\
$Z$ & ${ }^{0} \mathrm{G}_{\mathrm{Mg}: \mathrm{Y}: \mathrm{Zn}}^{Z}-28{ }^{0} \mathrm{G}_{\mathrm{Mg}}^{h c p} \mathrm{Mg}-7{ }^{0} \mathrm{G}_{\mathrm{Y}}^{h c p}-65{ }^{0} \mathrm{G}_{\mathrm{Zn}}^{h c p}$ & $=-2712500+1070 T$ & This work \\
& ${ }^{0} \mathrm{G}_{\mathrm{Mg}: \mathrm{Y}: \mathrm{Mg}}^{Z}-93{ }^{0} \mathrm{G}_{\mathrm{Mg}}^{h c p} \mathrm{Mg}-7{ }^{0} \mathrm{G}_{\mathrm{Y}}^{h c p}$ & $=-326810+465 T$ & This work \\
\hline
\end{tabular}


ISIJ International, Vol. 50 (2010), No. 12

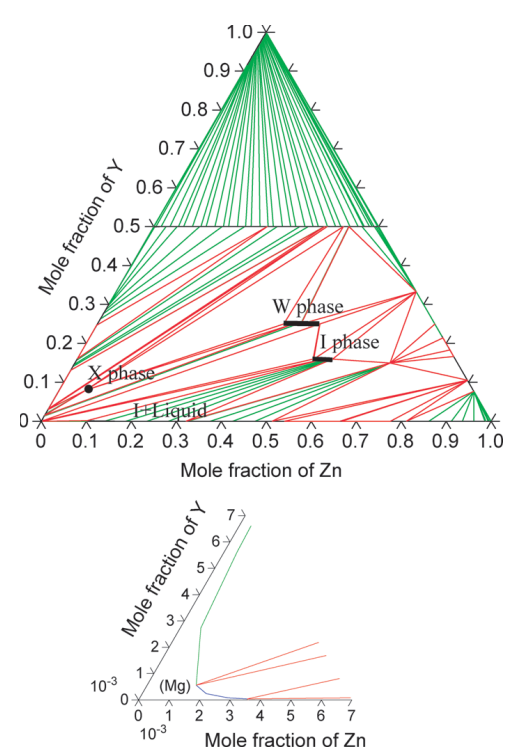

Fig. 3. The ternary isothermal phase diagram of the $\mathrm{Mg}-\mathrm{Zn}-\mathrm{Y}$ system at $833 \mathrm{~K}$ (top: overall phase diagram, bottom: maginified image at Mg-rich region). The black solid circles indicate the stoichiometric compounds of the $X$ phase. The bold solid line indicates the non-stoichiometric compounds of the $W$ and $I$ phase.

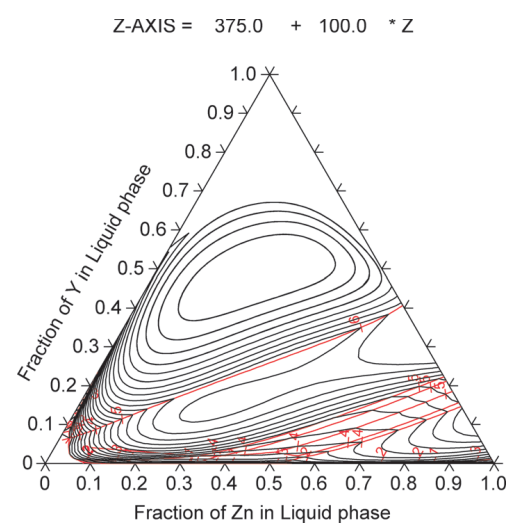

Fig. 4. The liquidus surface projection of the $\mathrm{Mg}-\mathrm{Zn}-\mathrm{Y}$ system. The red lines in the figure are monovariant lines, and the letters on red lines are $Z$ values shown above equation expressing temperature in Kelvin.

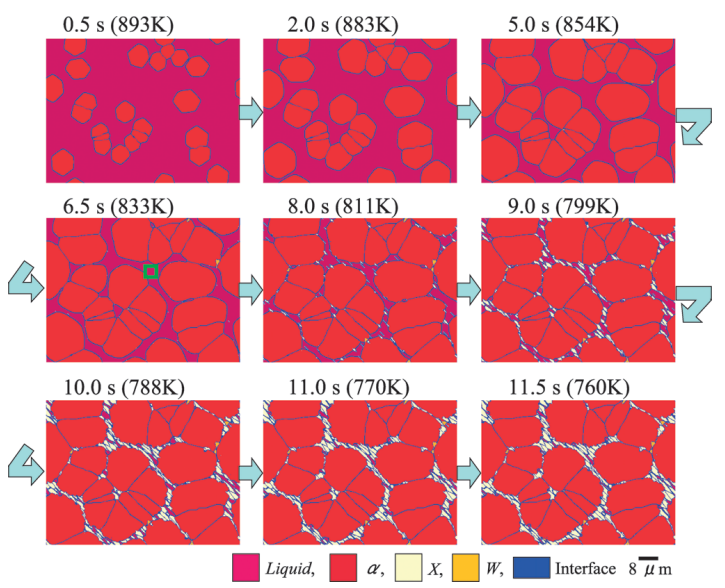

Fig. 5. The microstructure calculated with MICRESS software. The green rectangle in the picture of $6.5 \mathrm{~s}$ is a reference area to evaluate the compositions of the liquid phase, which is used in the zoomed in analysis.

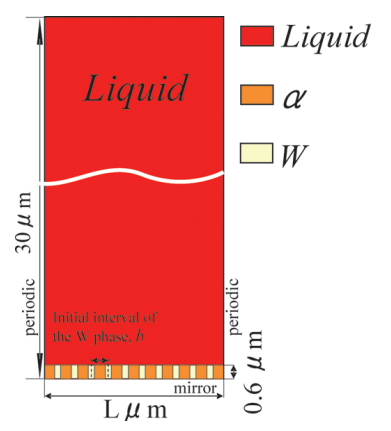

Fig. 6. The calculation model and boundary conditions.

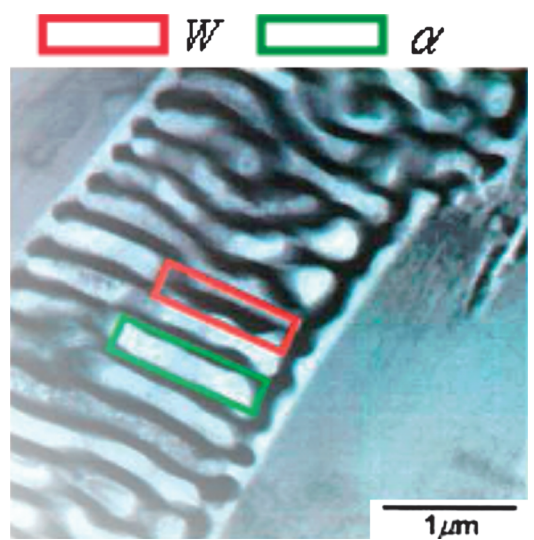

Fig. 7. The bright field image observed by TEM for lamellar microstructure.

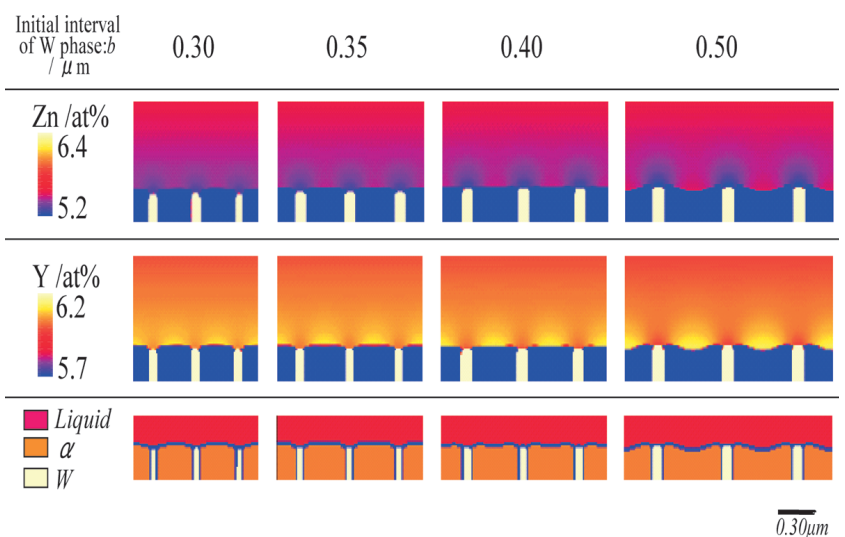

Fig. 9. The stable lamellar growth at $0.050 \mathrm{~s}$. In case that the initial interval length of the $W$ phase, $b$, is larger than $0.3 \mu \mathrm{m}$, the lamellar spacings keep the initial interval length.

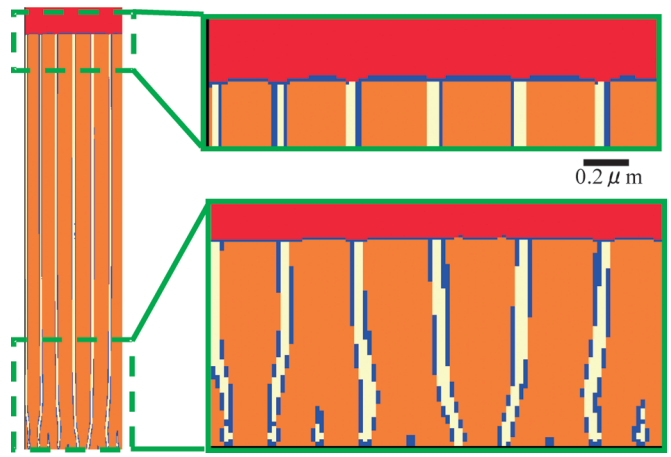

Fig. 10. The microstructure calculated by MICRESS software (left: the overall picture for the analysis) (right, top: final solidificated areas, after $10 \mathrm{~s}$ ) (right, bottom: initial stage of the solidification, after $0.05 \mathrm{~s}$ ). 
The interface energies are listed in Table 2. The $k$ for $\sigma_{\text {liquid-W }}$ was determined by the assumption that the $W$ phase has cubic crystal structure and the same value for the interface energy for $\sigma_{\alpha-X}$ and $\sigma_{\alpha-W}$ were applied.

\subsubsection{Formation of Microstructure \\ Solidification Process}

The simulation was started from a liquid state and then the $\alpha$ phase was nucleated in the liquid phase. The muitiphase-field simulation conditions are listed in Table 3 .

As cooling down the temperature the particles of the $\alpha$ and $W$ phase were appeared in the liquid phase, before the $X$ phase appeared as shown in Fig. 5, which is in good agreement with the experimental observations shown in Fig. 2. The solidification path derived from phase field calculation was the same as that from CALPHAD approach.

Then particular focus is placed on the formation behavior of the $X$ phase. The microstructure formation that liquid phase was changing into the $X$ phase.

\subsubsection{Multi Phase Field Modeling \\ Zoomed in Analysis}

As results of experimental measurement, a strong anisotropy of the $X$ phase has been observed on basal plane of matrix shown in Fig. 2. Thus the initial liquid composition of $\mathrm{Mg}-1.3 \mathrm{at} \% \mathrm{Zn}-1.6 \mathrm{at} \% \mathrm{Y}$ alloy were set for the analysis of zoomed in area (the value in the green box in Fig. 2 at $6.5 \mathrm{~s}(833 \mathrm{~K})$ ). The same amount of cooling rate compared to experimental conditions has been obtained by the heat extraction rate condition for the simulations. The calculation conditions are listed in Table 4.

Lamellar microstructures consisting of the $\alpha$ phase and the $W$ phase formed from a liquid phase were observed in the experiments as shown in Fig. 7.

The composition of the liquid phase for lamellar microstructure simulation was evaluated from the solidification simulation. The liquid composition at $833 \mathrm{~K}$ in the simulation was adopted for the calculation of zoomed in area. A moving grid algorithm which adapted the calculation domain to $5 \mu \mathrm{m}$ from the moving solid-liquid interface. The particles of the $W$ phases were embedded in the $\alpha$ phase matrix at the bottom of calculation domain. Initial interval of the $W$ phase was a parameter in this simulation. The nucleation of new grain was not taken into account. Figure 8 shows steady growth velocity as a function of initial $W$ phase interval length. A stable cooperative lamellar growth was observed with initial interval length from 0.3 to $0.5 \mu \mathrm{m}$ as shown in Fig. 9.

The steady growth velocity has a maximum value according to the balance of the curvature effect and the diffusion on the growing interface. The lamellar spacing at the maximum steady growth velocity is the same with the lamellar spacing evaluated by experiments, which is called as "optimum lamellar spacing". Figure $\mathbf{1 0}$ is results with initial interval of $0.2 \mu \mathrm{m}$. The optimum lamellar spacing was formed by the balance between the curvature effect and the diffusion on the growing interface. This simulated lamellar spacing in Fig. 9 quantitatively agrees with the experimental measurements shown in Fig. 7.
Table 3. The calculation conditions for multi-phase-field simulation.

\begin{tabular}{llll}
\hline \hline Interface & Energy $\left[\mathrm{J} / \mathrm{m}^{2}\right]$ & $\epsilon$ & $k$ \\
\hline$\sigma_{\text {liquid- } \alpha}$ & $1.0 \times 10^{-1}$ & 0.0057 & $6^{20)}$ \\
$\sigma_{\text {liquid-X }}$ & $1.2 \times 10^{-1}$ & 0.0667 & 2 \\
$\sigma_{\text {liquid-W }}$ & $1.2 \times 10^{-1}$ & 0.0133 & 4 \\
$\sigma_{\alpha-\alpha}$ & $2.2 \times 10^{-1}$ & & \\
$\sigma_{\alpha-X}$ & $1.5 \times 10^{-1}$ & & \\
$\sigma_{\alpha-W}$ & $1.5 \times 10^{-1}$ & & \\
\hline
\end{tabular}

Table 4. The calculation conditions for zoomed in area ( $b$ : initial distance interval of the $W$ phase).

\begin{tabular}{ll}
\hline \hline Description & Conditions \\
\hline Initial liquid composition & $\mathrm{Mg}-6.75 \mathrm{at} \% \mathrm{Zn}-5.40 \mathrm{at} \% \mathrm{Y}$ \\
Dimension & 2-dimensional \\
Temperature gradient & $0[\mathrm{~K} / \mathrm{m}]$ \\
$b$ & $0.2,0.25,0.3,0.35,0.4,0.5,0.7[\mu \mathrm{m}]$ \\
Area size & $\mathrm{L}[\mu \mathrm{m}] \times 30[\mu \mathrm{m}](\mathrm{L}=b \times 10)$ \\
Grid size & $0.01[\mu \mathrm{m}]$ \\
Interface thickness & $0.05[\mu \mathrm{m}]$ \\
Heat extraction ratio & $0\left[\mathrm{~J} / \mathrm{sec} / \mathrm{m}^{3}\right]$ \\
\hline
\end{tabular}

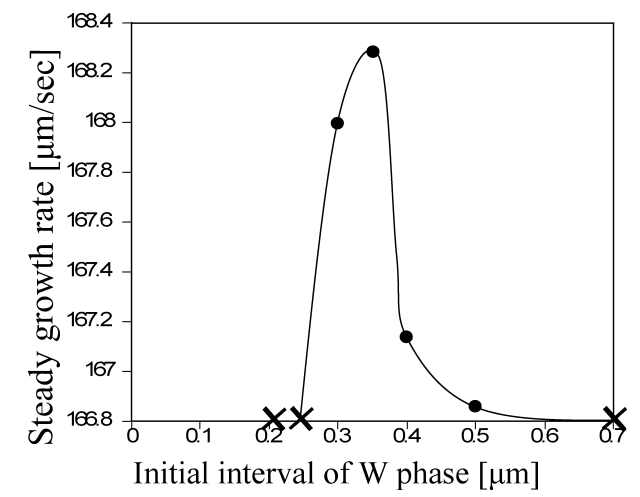

Fig. 8. The size dependency of growth rate of the $W$ phase stable lamellar growth, $\times$ : unstable lamellar growth, - : fitted curve). The $W$ phase grows stable with cooperative larger than $0.30 \mu \mathrm{m}$. The $W$ phase with initial interval less than $0.30 \mu \mathrm{m}$ grows resulting interval of $0.33 \mu \mathrm{m}$ for stable growth.

\section{Conclusions}

The microstructure formation of the $\mathrm{Mg}-\mathrm{Zn}-\mathrm{Y}$ system has been evaluated by means of experimental, CALPHAD technique and multi-phase-field method.

The experimental measurement of the solubility of the $\mathrm{Mg}$ and $\mathrm{Zn}$ elements in the $W$ phase has been carried out, and calibrated for the CALPHAD modeling to implement the thermodynamic model into the multi-phase-field method. The microstructures obtained by the multi-phasefield method coupled with revised CALPHAD thermodynamic database well explain the experimental measurements in the $\mathrm{Mg}-\mathrm{Zn}-\mathrm{Y}$ system. A result for lamellar microstructure simulation by the initial $W$ phase interval of $0.2 \mu \mathrm{m}$, the lamellar spacing in the simulation is about $0.33 \mu \mathrm{m}$, and experimental one is about $0.32 \mu \mathrm{m}$, which is in good agreement. The optimum lamellar spacing which gives the maximum steady growth velocity in the lamellar 
microstructure simulation quantitatively agrees with the lamellar spacing obtained by the experimental measurement.

\section{REFERENCES}

1) Y. Kawamura, K. Hayashi, A. Inoue and T. Masumoto: Mater. Trans., 42 (2001), No. 7, 1172.

2) T. Itoi, T. Seimiya, Y. Kawamura and M. Hirohashi: Scr. Mater., 51 (2004), No. 2, 107.

3) A. Inoue, Y. Kawamura, M. Matsushita, K. Hayashi and J. Koike: $J$. Mater: Res., 16 (2001), No. 7, 1894.

4) D. Bae, M. Lee, K. Kim, W. Kim and D. Kim: J. Alloys Compd., 342 (2002), No. 1-2, 445.

5) G. Shao, V. Varsani and Z. Fan: Calphad, 30 (2006), No. 3, 286.

6) S. Fries and T. Jantzen: Thermochim. Acta, 314 (1998), No. 1-2, 23.

7) R. Masumoto, H. Ohtani and M. Hasebe: J. Jpn. I Met., 73 (2009), No. 9, 683.

8) T. Horiuchi, A. Ono, K. Yoshioka, T. Watanabe, K. Ohkubo, S. Miura, T. Mohri and S. Tamura: Mater. Trans., 49 (2008), No. 10, 2247.

9) J.-O. Andersson, T. Helander, L. Hoglund, P. Shi and B. Sundman:
Calphad, 26 (2002), No. 2, 273.

10) I. Steinbach, F. Pezzolla, B. Nestler, M. Seeßelberg, R. Prieler, G. Schmitz and J. Rezende: Physica D: Nonlinear Phenomena, 94 (1996), No. 3, 135.

11) O. Redlich and A. Kister: Ind. Eng. Chem., 40 (1948), No. 2, 345.

12) J. Eiken, B. Boettger and I. Steinbach: Phys. Rev. E, 73 (2006), No. 6, 066122 .

13) A. Singh, M. Nakamura, M. Watanabe, A. Kato and A. Tsai: Scr. Mater., 49 (2003), No. 5, 417.

14) S. Yi, E. Park, J. Ok, W. Kim and D. Kim: Micron, 33 (2002), No. 6, 565.

15) D. Bae, S. Kim, W. Kim and D. Kim: Mater. Trans., 42 (2001), No. $10,2144$.

16) A. Borgenstam, L. Hoglund, J. Agren and A. Engstrom: J. Phase Equilib. Diff., 21 (2000), No. 3, 269.

17) The Japan Institute of Metals, Databook of Metal, (2004), 22.

18) T. Nishizawa: Thermodynamics of Microstructures, ASM Int'l., Ohio, (2008), 126.

19) R. A. Swalin: Wiley-Interscience, New York, (1972).

20) B. Boettger, J. Eiken and I. Steinbach: Acta Mater, 54 (2006), No. $10,2697$. 